the nature of medical ethics, patients' rights and the doctor-patient relationship, and rights and health care. While there are no designated sections on truth-telling, consent or confidentiality, these basic themes are integrated throughout the volume in the context of specific issues. The result is not short shrift on these important principles but rather nuanced qualifications on their meaning and complexities when attempts are made clinically to implement them. A sampling of five professional codes of ethics is provided which I would not find adequate but this shortcoming could easily be remedied by supplementing with the International Code of Medical Ethics, the Declaration of Geneva and the Declarations of Hawai, Oslo and Tokyo. The American Medical Association's Principles of Medical Ethics included is the widely publicised 1957 Code. However, the AMA House of Delegates have now prepared a report including a draft of a new set of seven principles to replace the existing list of ten. While publication of the new draft had not occurred at the time of writing this review, the new draft form is encouraging in its shift of emphasis to an ethic based on notions of rights and responsibilities rather than benefit and harm. Undoubtedly, we can look forward to much debate and dispute on the new draft before final endorsement is given.

A central difficulty in compiling an anthology of medical ethics is the speed with which it becomes outdated. Although first published in 1978, the vast majority of the articles were written prior to 1976 . This may be inevitable given the time lag required between compiling articles and actual publication and, indeed, some of the articles which are less dependent on empirical research and more focused on conceptual analysis can withstand the hazard of being outdated. The area which would most require supplementation to update is, paradoxically, one of the more probing sections of the volume (in its attempt to discuss the serious ethical issues with clarity)-eugenics and genetics. Included in this section are discussions of human in vitro fertilisation, discussions which ironically assumed that success in this highly researched area was very remote.

However, the birth of Louise Brown on 25 July 1978 startled those who assumed that human in vitro fertilisation and embryo transfer was a piece of remote science fiction. I suspect that her satisfactory progress to date, showing all standard indications of normalcy, has also caused chagrin to some who looked upon this procedure as inevitably resulting in abnormalities or deformities. The emotive, pejorative language of 'deliberate manipulation of a human embryo' exposes the bias of Leon Kass' assessment of the in vitro procedure. The language of 'manipulation' (used too frequently in ethical discussions) connotes a firm suspicion that certain research is another instance of glory-seeking hubris on the part of research scientists. Kass is careful to qualify his concern with an appeal to the medical profession as a whole to see that a minimal requirement be met by all researchers in this delicate area. In vitro fertilisation, he argues, needs yet to be successfully and regularly accomplished in species more closely related to humans $e g$, in primates. This requirement is now history and it is likely that researchers will feel post-facto justified in working towards continued success at the human level. However, this present surge of confidence does not retrospectively answer the question of whether Steptoe and Edwards proceeded ethically in their experiments on the unborn. Only a thorough-going consequentialist ethic would assess the morality of a method by the single criterion of success in the outcome. In fact, some of the more sceptical are still not willing to say that Louise Brown's birth was a success, on the assumption that there could still be developmental complications and these, they hypothesise, may be the result of her 'unnatural' type of conception.

Serious objections to in vitro fertilisation are further made on the grounds that the procedure is not therapeutic but rather clearly experimentation on unborn children and, it is agreed, we have regulations governing such experimentation. But this objection is often muddled by confusions about who is undergoing and consenting or not consenting to the procedure. Those who see the procedure being done on an unborn child (as Kass does) conclude that the potential and serious unknown risks to the unborn constitute unjustified experiment rather than potentially beneficial therapy. Those who see the procedure as primarily therapeutic see the consenting $\frac{2}{\mathrm{n}} \mathrm{d}$ informed subjects to be the husb ind and wife. In vitro fertilisation $\overline{\text { Dion }}$ these terms is analogous to the artificial insemination of a wife $\overline{\bar{x}}$ ith the husband as donor. The Jimmediate purpose is to enable a comple who are prevented from concei because of physiological obstacles to have a child. The experimenal/ therapeutic assessment of humagy in vitro fertilisation hinges ultimately on one's assessment of the status of the fertilised ovum and its inability to give consent.

w

Finally, the section on eugenics and genetics is considerably weakened by not incorporating discussion of recombinant DNA researchisits objectives, prospects and the 6 benefit questions. One of the autbors alludes to the research but prescinds from discussing it since it has already been widely publicised. But fone reason for an anthology is $\mathbb{D}$ to condense such discussion and clasify the issues in readable form. With these provisos, I find the selection of readings effectively fulfil the edie r's laudable objective which I happer to share when teaching ethics to medical students.

D DOOLEY-CL ARKE

\section{Compliance in health care}

Edited by R Brian Haynes, D Wayne Taylor and David L Sackett, J hins Hopkins University Press, Ig79, 516 pp, \$25.00.

Anatomy of an Illness, as Perceived by the Patient: Reflections on Health and Regeneration

Norman Cousins, W W Norton \& Co, London, r980, I73 pp, £5.75.

The size of the volume on compliasce in health care and the fact that over one third of it comprises an annotgted bibliography of over fourteen hundred references testifies to sthe growing significance of this subject. Since it deals with the whole question of how far a persgn's behaviour coincides with meefical advice and with the strategies wigich may be employed to persuade patients to take their medicines and obey doctor's orders the topic chas sinister connotations of manipulation and control. For this reasonothe distinguished editors are rightly 
anxious to affirm their own ethical standards. They personally would refuse to countenance attempts to 'change compliance behaviour' unless three preconditions are met, namely that the diagnosis is correct, that the proposed therapy or course of action will do more good than harm and, finally, that the patient is an informed, willing partner in the process of behaviour change.

The development of effective drug treatments for a number of chronic conditions (especially hypertension) and the recent realisation of the impact which certain life styles can have upon health have forced physicians to take note of what is actually an age-old phenomenon. People have always treated themselves, all primary care begins and continues at home and it is well-nigh impossible for even the most conscientious and ethical of clinicians to ensure complete obedience to his will. Patients persist in making their own decisions, they pick and choose, fall in with regimes or drop out of experiments, for reasons which testify to their preoccupation with other human goals and the different ways they sort symptoms and misfortunes.

The book is intended as a practical guide to doctors and medical research workers who sincerely wish to get better results or, at least, to realise when and to what extent their best laid plans are being frustrated. In spite of the editors' disclaimers there are inherent paradoxes in this whole business, as Jonsen's chapter on ethical issues clearly demonstrates. The doctor as moralist or concerned carer is confronted with his patient's ultimate freedom to persist in sin and ill health. In fact, there are limits to the ethical responsibility which the physician can and should adopt, even if he thinks he knows best what someone needs. Furthermore, researches into non-compliance are bound to rely on deception since, if they know they are being watched, people will change their behaviour. Doctors themselves are far from perfect, their knowledge is often limited and they are given to authoritarianism and the sin of pride. Feinstein, a famous bio-statistician, wryly observes in his chapter that, to acquire the data needed for ruling out the existence of compliance bias, investigators will have to 'restore attention to a traditional activity of clinical medicine - talking to the patient'.
One patient, who speaks for himself is Norman Cousins. Although claiming to anatomise his illness he leaves its medical nature extremely vague, it simply appears that he developed a painful, disabling condition to which most doctors attached the direst prognosis. However, he resolutely refused to accept either their drugs or their pronouncements of doom. Believing literally that laughter was the best medicine, he abjured aspirin and embarked instead upon a regime of comic/cuts, in the form of Candid Camera replays, liberally supplemented with huge doses of Vitamin C. His own personal physician surprisingly complied with his unorthodox medication and, eventually, the symptoms disappeared. Cousins naturally attributed this fortunate outcome to his own confident control of affairs. The book preaches the importance of states of mind in hastening the body's natural powers of recuperation. Epidemiologists and students of compliance are bound to view this one-off experiment with profound scepticism and disapproval. But the book is a triumphant paean to selfhelp and the author, who ranges over many related topics, is in fact severely critical of the excesses of the holistic health movement, beset as it is by schisms and contradictions. As a detailed account of how one patient took the law into his own hands and cheerfully disobeyed doctors' orders Cousins, personal story is at the opposite extreme from the large scale statistical surveys of illness which are the basis for most studies of awkward patients' behaviour.

UNA MACLEAN

\section{Medical Experimentation: its legal and ethical aspects}

Edited by Amnon Carmi. Turtledove Publishing Limited, Ramat Gan, Israel, I979, I48 pp, \$12.50.

The book consists of an Introduction by Judge Amnon Carmi, six chapters on the medical and psychiatric aspects of medical experimentation, four chapters on the legal aspects of experimentation and one chapter apiece on ethical aspects and religious aspects.

In the first chapter 'The challenge of experimentation' Amnon Carmi advocates compulsory experimentation; 'it is, therefore, desirable that minors and mental patients take part in the general compulsory exper- imentation of the community at large, as we will be suggesting below'. 'It is important to mention that there will be no need to cancel the prevailing arrangements concerning the individual volunteering for an experiment on his body, even after the public is legally required to take part in general medical research'.

Judge Carmi's almost total disregard of the principles laid down in most of the accepted ethical codes is further underlined by his statement 'there is no real difference between the prevailing authority of society to deprive the prisoner of his freedom and the authority to force him to participate in an experiment'.

The meaning of passages in this chapter is often obscure; $\mathrm{eg}$, on page 7 'Due to their acculturation, members of society are unaware of the fact that their freedom does not carry its significance'.

Under the section headed 'Carrying the decision into effect' a list of 20 topics is given. The last five under the heading are as follows:

a) Financing the research.

b) Organising of the research

c) Compensation for damage caused by research

d) Enforcement of research

e) Stages of carrying the whole plan into effect.

Apart from the natural distaste engendered by the words 'Enforcement of research', the underlying principle contravenes directly, rules I and 9 of the Nuremberg code. The aim of the code was to be sure that certain basic principles must be observed in order to satisfy moral, ethical and legal concepts. Seven German experimentalists were condemned to death for ignoring the principles of this code.

David M Maeir deals superficially with the perennial problem of 'Informed Consent'. He states that the literature regarding informed consent is enormous. (Ninety-nine per cent of it discussing what ought to happen and only a small fraction describing what does in practice happen) but gives only seven references, four more than ten years old and the latest six years old. His categorical statements would not meet with general agreement. He highlights the problem of experimentation relating to the fetus by pointing out that when killing is the issue, the fetus seems to belong to the mother; when experimentation is the issue, the rights of the fetus are inviolate. 